\author{
CYNTHIA WHISSELL \\ Laurentian University, Sudbury, Ontario
}

\author{
LEADING WITH WORDS? \\ EMOTION AND STYLE IN THE LANGUAGE OF \\ U.S. PRESIDENT CLINTON'S PUBLIC COMMUNICATIONS
}

\begin{abstract}
Samples of U.S. President Clinton's public communications were scored with a computer program for the emotional undertones of their words, for the proportional occurrence of negations and very common words, and for the use of first and second person pronouns. The first two measures address emotion, the remaining ones style. Measures successfully discriminated ( $97 \%$ correct classification) formal communications from informal ones and informal communications where the President was physically present with his audience from those where he was not $(90 \%)$. Classification for two sets of validation samples was very strong $(90 \%)$. Measures discriminated President Clinton's Executive Orders from President G. W. Bush's. Discriminant functions based on emotional measures alone were almost as successful as those including measures of style (no more than $8 \%$ fewer correct classifications). Results are interpreted in terms of theories of persuasive presidential rhetoric.
\end{abstract}

Key words: President Clinton's communication, public communication, presidential style of language, persuasive presidential rhetoric

\title{
Introduction
}

This paper examines the emotion and style of language used by U.S. President Clinton in various public communications during the eight years of his presidency. The communications of speakers occupying offices of high rank tend to be intentional with respect to effect rather than accidental. Seligman (2002) refers to the pressure exerted on a speaker's language by his position as a "genre imperative." Both emotion (e.g., de Landtsheer, de Vries, \& Vertessen, 2008) and style (e.g., Halmari, 2008) influence the impact of presidential communications, which have been employed to describe presidents' reactions to personal (e.g., Simons 2000) and national (e.g., Bligh, Kohles, \& Meindl 2004a, b) crises. Since the events associated with Nixon's resignation, a special fascination has attached to less formal com-

Address for correspondence: Cynthia Whissell, Laurentian University, 935 Ramsey Lake Road, Sudbury ON P3E 2C6, Canada. E-mail: cwhissell@laurentian.ca 
munications, in part because these are assumed to be less subject to impression management (Sigelman, 2001).

Informal communications (e.g., remarks) are generally delivered orally and offer more opportunities for deviation from an established script. In contrast, formal communications (e.g., executive orders) are delivered in writing and take their final form well before the moment of delivery. Recipients of formal communications tend to be more expert than members of the broad audiences to whom remarks, speeches, and radio talks are addressed. Researchers discussing the rhetorical presidency (e.g., Whittington, 1997) have emphasized the manner in which presidents employ informal communications to recruit public opinion. This article describes the general tone of President Clinton's communications, and addresses the hypothesis that the emotion and style of these communications would vary as a function of the type of communication.

\section{Ghosts in the Machine}

A discussion of presidential communications is bound to prompt the mention of writers and the role they play in "scripting" presidents. Although writers make frequent contributions, presidents are responsible for their own communications in that they at least act as a filter for them. Presidents shape materials prepared by others to their own purposes. Sigelman (2002) demonstrated consistency of a presidential "voice" even when speech writers were added to the equation. He also noted that speech writers did influence the emotional tones of the final product. President Clinton's involvement in the preparation of his own communications is recognized (Harris, 1999), but these communications also came under the influence of advisors. The study of "President Clinton's communications" is therefore the study of a product identified with the President, and delivered by the President, but one which may have been exposed to other sources of influence.

\section{Quantifying Presidential Communications}

Different analytical methods have been applied to the study of presidential communications. Jacobs, Page, Burns, McAvoy, and Ostermeier (2003), for example, coded Nixon's communications in terms of policies and symbols. Simons (2000) and Bligh et al. (2004a, b) focused on rhetorical analysis while Sigelman (2001), Whissell \& Sigelman (2001), and Sigelman and Whissell (2002a, b) employed computer programs. This research quantifies presidential communication with the help of computer programs.

President Clinton's communications were quantified in terms of the Pleasant (or Unpleasant) and Active (or Passive) undertones of their words. To these two emotional measures, scored by the Dictionary of Affect in Language (Whissell, 2009), were added the stylistic measures of Imagery (also scored by the Dictionary), and the proportional use of negations and very common words. In contrast to simple language, complex language is low in Imagery and it includes few 
common words. The employment of negations such as "no" and "not" is known to influence persuasion (Grant, Malaviya, \& Sternthal, 2004), and to play a role in presidential rhetoric (Seyranian \& Bligh, 2008). President Clinton's communications were scored for the presence of negations. A final triplet of measures involved the proportional use of first person singular (e.g., I), first person plural (e.g., we) and second person (e.g., you) pronouns. Analysts have noted audiences' positive reactions to inclusive first person plural pronouns ("we" as opposed to "you" or "I"); they have also discussed President Clinton's use of such pronouns (Halmari, 2008; Teten, 2007).

President Clinton's emotion and style were compared to normative values describing a broadly sampled corpus of everyday English (Whissell, 1998) in terms of the eight measures described above. Three types of communications (formal and informal with and without the physical presence of the speaker) were studied. A number of comparisons were conducted in order to eliminate possible confounds. Although it was hypothesized that formal communications would include more complex language than informal ones, it could be argued that formal communications such as executive orders are more a function of the office than the person of the president. To address this argument, President Clinton's executive orders were compared to a pre-9/11 set of President G. W. Bush's. As an additional check on the data, President Clinton's communications were classified as occurring before or after his impeachment hearings (which lasted from December 1998 to February 1999), and the two sets of communications were compared.

\section{Method}

\section{Materials}

President Clinton's communications were downloaded from his web site (http://www.clintonpresidentialcenter.org) in September and October of 2004. Only communications attributed in their entirety to President Clinton were included in the study. Samples of all the three types of communication were selected randomly, without replacement, from among those available. The first materials studied included 20 presidential Remarks and 20 Radio Talks, which were classified as informal communications, and 20 Executive Orders, which were classified as formal ones. A validation set for the planned discriminant function analysis comprised seven additional randomly selected communications from each of these categories. A second validation set, again randomly selected, comprised 10 Letters to Congress (formal) and 10 Speeches (informal): to this was added an excerpt from the first chapter of President Clinton's autobiography My Life (available on his web site on October 2, 2004; informal). President G. W. Bush's 24 pre-9/11 Executive Orders were downloaded from the White House site in 2005. This site has since been discontinued, but the orders are available electronically on the President's 
library site (http://www.georgewbushlibrary.gov/). In total 126 communications and 132,529 words were scored and studied.

\section{Scoring}

The Dictionary of Affect in Language contains 8742 words rated by volunteers in terms of their connotative meaning and their imagery. The Dictionary corpus was established in an ecologically valid manner through the sampling of natural language sources (Whissell 2009). Each Dictionary word is represented by a rating on a three-point scale for Pleasantness (how pleasant the word seems), Activation (how active or aroused the word seems), and Imagery (how easily people are able to form a mental picture of the word). The Dictionary of Affect has been used to score many different types of natural language samples including presidential inaugural addresses (Whissell \& Sigelman, 2001), and the Declaration of Independence (Whissell, 2002). Dictionary scoring is performed by a computer program that matches each individual word in a sample to the Dictionary, and imports values associated with scored words into a data file. Scores were imported for $93 \%$ of all words in the study; the normative value is $90 \%$ (Whissell, 2009).

In Dictionary scoring, a document would receive high scores for Pleasantness if it included many words such as "understand," "health" and "feel," which were rated high in Pleasantness and avoided words such as "uncomfortable," "cost" and "ignored," which were rated low. It would receive high scores for Activation if it included many words such as "calling," "told," and "enjoy," which were rated as high in Activation, and avoided words such as "position," "month," and "late," which received low ratings. Concrete documents would include predominantly easily imaged or imagined words such as "people," "doctors," and "companies," and few abstract or difficult-to-envision words such as "denied," "ought," and "think." All these examples were drawn from President Clinton's Remark \#184, which was scored for this research.

The use of negations (such as "no," "not," and “-n't") in each communication and the use of very common words were tallied by a computer program and expressed as a proportion of the total number of words. Very common words (e.g.,"is", "the," "can") are those with a frequency greater than 300 per million words of natural language (Whissell, 1998). The use of first person singular, first person plural, and second person pronouns were also counted by a program and expressed as proportions.

\section{Normative (Everyday English) Corpus}

The normative corpus to which the President's communications were compared was a broadly sampled corpus of 348,000 words (Whissell, 1998). It was designed to represent "everyday English," and it sampled from written and oral sources including newspaper articles, televised programs, books, essays, and discourse during meetings. Significant differences from this corpus for any category of communication would indicate that communications were stylistically or emotionally extreme - that 
Table 1. Means and standard errors (in parentheses) for the normative corpus and for groups of formal and informal documents

\begin{tabular}{lcccccccc}
\hline \multirow{2}{*}{ Group } & \multicolumn{7}{c}{ Measure } \\
\cline { 2 - 8 } & $1 \mathrm{ps}$ & $1 \mathrm{pp}$ & $2 \mathrm{p}$ & Pls & Act & Img & Neg & Vcom \\
\hline Normative & 0.027 & 0.007 & 0.011 & 1.848 & 1.671 & 1.532 & 0.016 & 0.651 \\
Corpus & & & & & & & & \\
& & + & & & & - & - & \\
Remarks & 0.024 & 0.022 & 0.012 & 1.856 & 1.679 & 1.487 & 0.011 & 0.651 \\
& $(.003)$ & $(.003)$ & $(.004)$ & $(.012)$ & $(.008)$ & $(.011)$ & $(.002)$ & $(.022)$ \\
& - & + & - & + & + & & - & - \\
Radio & 0.009 & 0.035 & 0.006 & 1.862 & 1.703 & 1.556 & 0.007 & 0.618 \\
Talks & $(0.001)$ & $(0.003)$ & $(0.002)$ & $(0.005)$ & $(0.005)$ & $(0.013)$ & $(0.001)$ & $(0.011)$ \\
& - & - & - & - & & - & - & - \\
Executive & 0.007 & 0.001 & 0.000 & 1.796 & 1.676 & 1.494 & 0.005 & 0.456 \\
Orders & $(0.002)$ & $(0.000)$ & $(0.000)$ & $(0.007)$ & $(0.009)$ & $(0.014)$ & $(0.001)$ & $(0.007)$ \\
\hline
\end{tabular}

ps: proportion of first person singular pronouns

1pp: proportion of first person plural pronouns

2p: proportion of second person pronouns

Pls: Pleasantness

Act: Activation

Img: Imagery

Neg: proportion of negations

Vcom: proportion of very common words

+ : significantly higher than the normative corpus (t-test, two-tailed, $\mathrm{p}<0.05$ )

-: significantly lower than the normative corpus ( $t$-test, two-tailed, $\mathrm{p}<0.05$ )

they contained language different from the language that a North American would normally encounter in everyday life.

\section{Results}

\section{The Tone of President Clinton's Communications}

Table 1 reports means for all measures to three significant digits, and results from comparisons of these means to the normative corpus. President Clinton's Remarks were closest in emotion and style to the everyday norm, though they included proportionally more instances of first person plural pronouns, lower Imagery, and proportionally fewer negations. The President's Radio Talks differed from the norm for most measures. They included fewer first person singular and 
Table 2. Standardized canonical discriminant function coefficients and outcome measures for eight stepwise discriminant function analyses predicting type of document from measures of emotion and style

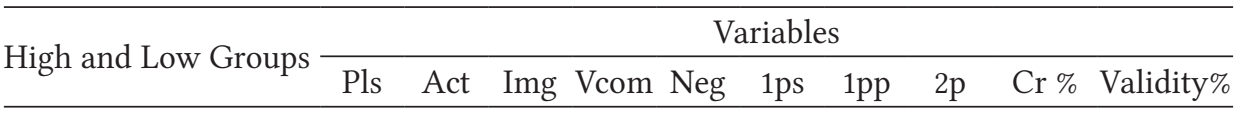

Discriminant Functions Including both Emotional and Stylistic Predictors

\begin{tabular}{|c|c|c|c|c|c|c|c|c|}
\hline \multirow{2}{*}{\multicolumn{2}{|c|}{$\begin{array}{l}\text { Lo: Formal } \\
\text { Hi: Informal }\end{array}$}} & 0.54 & 0.99 & & & 0.49 & 0.8897 & $100 ; 100$ \\
\hline & & & & & & & & \\
\hline \multicolumn{2}{|l|}{ Lo: Remarks } & 0.68 & & 0.56 & -0.73 & 0.34 & 0.7190 & $79 ; 82$ \\
\hline \multicolumn{9}{|l|}{ Hi: Radio } \\
\hline Lo: Bush & 0.72 & & -0.56 & 0.52 & 0.36 & & 0.4673 & \\
\hline \multicolumn{9}{|l|}{ Hi: Clinton } \\
\hline Lo: Post- & & & & 0.50 & & $\begin{array}{ll}-0.51 & 0.79\end{array}$ & 0.3464 & \\
\hline
\end{tabular}

Discriminant Functions Based on Emotional Predictors Alone

Lo: Formal

Hi: Informal

Lo: Remarks

1.00

Hi: Radio

Lo: Bush

Hi: Clinton

Lo: Post-

1.00

Hi: Pre-

Impeachment

$\mathrm{p}<0.05$ for all discriminant functions except the last, where $\mathrm{p}<0.10$

Hi: group scoring high on the composite discriminant score

Lo: group scoring low on the composite discriminant score

Pls: Pleasantness

Act: Activation

Img: Imagery

Neg: proportion of negations

Vcom: proportion of very common words

1ps: proportion of first person singular pronouns

1pp: proportion of first person plural pronouns

$2 \mathrm{p}$ : proportion of second person pronouns

Cr: canonical correlation

$\%$ : percent of cases correctly classified

Validity\%: percent of cases correctly classified in the two validation samples 
second person pronouns but more first person plural pronouns. They were more Pleasant and Active than the corpus, but they contained fewer negations and very common words. The language of the Radio Talks was pleasant, active, concrete, and inclusive. Executive Orders fell below the norm for all measures except Activation, where there was no difference. The Orders were somber, impersonal, and complex communications.

\section{Discriminating Among Groups of Communications}

Table 2 summarizes the results of various stepwise discriminant function analyses. Those discriminating formal from informal documents were conducted on the first 60 cases, and were evaluated in terms of their classification performance on the two validation samples, each of which included 21 cases. Formal documents were easily discriminated from informal ones ( $97 \%$ accuracy), and the formula generalized well to both validation samples $(100 \%, 100 \%)$. According to the standardized canonical discriminant function coefficients in the first row of Table 2, informal documents were identified on the basis of higher Imagery and a greater use of very common words, along with a greater use of first person plural pronouns (concreteness, simplicity, and inclusivity).

Remarks, where the president was physically present, were successfully discriminated from Radio Talks, where he was not (second row of Table 2; 90\% correct classification in the original samples, $79 \%$ and $82 \%$ in the validation samples). A combination of high Imagery, the more frequent use of negations, a lesser use of first person singular pronouns, and a greater use of first person plural pronouns, characterized Radio Talks.

President Bush's Executive Orders were shorter than President Clinton's (521 versus 710 words each). The third row of Table 2 describes the prediction of presidential attribution (Clinton or Bush) for Executive Orders. This prediction was 73\% accurate: a weighted sum representing Pleasantness, the lower use of very common words, and the higher use of first person singular pronouns and negations led to the prediction of President Clinton as the author. The only univariate difference was the one associated with Pleasantness, which had the strongest weight in the formula. Executive orders were identified as originating with President Bush if they were more unpleasant, used more common words, and avoided words such as "I" and "not."

President Clinton's pre- and post-impeachment communications were weakly but significantly discriminated (64\%) by a function based on the more frequent use of common words and second person pronouns, and the less frequent use of first person plural pronouns. Communications including fewer very common words, more inclusive first person pronouns and fewer second person pronouns were classified as post-hearing communications.

Emotion entered as a significant predictor in only one of the first four equations in Table 2. Most significant predictors were stylistic. Four additional stepwise 
discriminant function analyses, also summarized in Table 2, were conducted on the basis of emotional measures alone in order to assess the discriminating power of these measures. The correct assignment of cases to conditions in the main and validation samples was lower, but not much lower, when the six stylistic measures were ignored in favor of two emotional ones. A single measure entered each discriminant function. Higher Pleasantness predicted an informal rather than formal communication, higher Activation predicted a Radio Talk rather than a Remark, higher Pleasantness predicted President Clinton rather than President Bush as an author of an Executive Order, and higher Activation predicted a pre- rather than a post-impearhment communication. On the average, excluding the six stylistic measures from the discriminant function resulted in a less than $8 \%$ decrease in correct classification. Correlations between emotional and stylistic measures were moderate $(r<0.65$, median $=0.41)$, indicating that the shared variance among measures was modest $(<42 \%$, median $=17 \%)$.

\section{Discussion}

This research described and classified random samples of U.S. President Clinton's public presidential communications on the basis of their emotion and style. It included two validation sets, one similar to, and one different from the sets originally classified by discriminant functions. These design features attest to the generalizability of the study's inferences, which are further strengthened by the agreement of current findings with those from previous research. President Clinton did use emotionally colored language (Whittington, 1997), and his communications included words which were relatively active and positive (Sigelman \&Whissell, 2002a). Halmari's (2008) and Teten's (2007) conclusion that Clinton employed inclusive first person plural pronouns rhetorically was confirmed. President Clinton responded to genre imperatives (Seligman, 2002) by employing a higher level of complexity in formal communications. There was a relative simplicity in the language of current presidential communications intended for wide audiences (Whissell \& Sigelman, 2001).

It is at one and the same time true that "presidential rhetoric is subject to influences that may have little or nothing to do with a president's personality" (Sigelman, 2002 , p. 840) and that "much can be learned about presidents through the words they utter in public" (p. 850). These two are the "half-empty" and "half-full" versions of statements relating presidential personality to presidential rhetoric. Multiple influences impact on presidential communications: these include the situation of the communication, the need to present an appealing image, and the preferences of the president involved. The data studied here provide evidence of several such influences. President Clinton's formal or official communications (Executive Orders, Letters to Congress) tended to employ language that was relatively unpleasant and complex. In comparison to these, his more casual communications (Speeches, 
Remarks, Radio Talks, and Autobiography) employed more pleasant language and more common words. Informal communications fell into two classes: those where the President was physically present during delivery (Speeches, Remarks), which were more passive in tone and more abstract, and those where he was physically absent (Radio Talks, Autobiography), which were more active in tone and more concrete. These two categories of communication may also have been different in terms of the amount of preparation associated with the communications and opportunities for spontaneity.

The role played by measures of style in the prediction schemes of the research, and especially in the prediction of formality, was fully expected. It is notable, however, that emotion alone was capable of discriminating President Clinton's formal (less Pleasant) from his informal (more Pleasant) communications, and informal communications where he was physically present (less Active) from those where he was not (more Active). Emotion also discriminated President Clinton's executive orders (more Pleasant) from President Bush's (less Pleasant) and President Clinton's pre-impeachment communications (more Active) from his post-impeachment ones (less Active). Emotion varied as a function of type of communication, physical presence, President, and events in the life of the President: it was central, not peripheral to the message being communicated.

In the style of presidency labeled as rhetorical, presidents are assumed to address the general public informally, and to seek support for their agendas from it. According to Whittington (1997), President Clinton used emotionally colored interactions to wage an ongoing campaign for public support throughout his presidency. Conclusions of the research in this paper indicate that in informal communications addressed to the general public, President Clinton spoke more pleasantly, more inclusively, and in simpler language than he used in formal communications. Furthermore, in pre-planned appeals where he was not physically present, the President used more rousing language, and had greater recourse to visual imagery. Although these results support the conclusion that the President and/or his advisors were crafting his communications for effect, they do not attest to the specific motivations involved.

The word "demagogue" has pejorative implications in Western society so that an accusation of "demagoguery" would be intended as an insult. From a definitional perspective, however, a demagogue is merely a leader who leads by persuasion of the public, and Teten (2007) affirms that all American presidents, including the founding fathers, sought to persuade the public and win its approval. The nature of communication media and the definition of democracy are both in flux (Carey, 1993), and methods of presidential communication are being constantly updated (as, for example, in the use of blogs). The rights of the public to discuss political matters lie at the root of the First Amendment of the U.S. Constitution, and they include the right to interact with the president in informal modes (Carey, 1993). In this political climate, presidents should be expected to manipulate the emotional 
and the stylistic contents of their communications in accordance with their audience and medium.

\section{References}

Bligh, M.C., Kohles, J.C., \& Meindl, J.R. (2004a) Charisma under crisis: Presidential leadership, rhetoric, and media responses before and after the September $11^{\text {th }}$ terrorist attacks. The Leadership Quarterly, 15, 211-239.

Bligh, M.C., Kohles, J.C., \& Meindl, J.R. (2004b) Charting the language of leadership: A methodological investigation of President Bush and the Crisis of 9/11. Journal of Applied Psychology, 89, 562-574.

Carey, J.W. (1993) The mass media and democracy: between the modern and the postmodern. Journal of International Affairs, 47, 1-21.

Grant, S.J., Malaviya, P. \& Sternthal, B. (2004) The influence of negation on product evaluations. Journal of Consumer Research, 31, 583-591.

Halmari, H. (2008) On the language of the Clinton-Dole presidential campaign debates. Fournal of Language and Politics, 7, 247-270.

Harris J.F. (1999) Cooking up the word stew. Washington Post, January 19, 1999, page A6.

Jacobs, L.R., Page, B.I., Burns, M., McAvoy, G., \& Ostermeier, E. (2003) What presidents talk about: the Nixon case. Presidential Studies Quarterly, 33, 751-771.

de Landtsheer, C., de Vries, P., \& Vertessen, D. (2008) Political impression management: How metaphors, sound bites, appearance effectiveness, and personality traits can win elections. Fournal of Political Marketing, 7, 217-238.

Seyranian, V. \& Bligh, M.C. (2008) Presidential charismatic leadership: exploring the rhetoric of social change. The Leadership Quarterly, 19, 54-76.

Sigelman, L. (2001) The presentation of self in presidential life: Onstage and backstage with Johnson and Nixon. Political Communication, 18, 1-22.

Sigelman, L. (2002) Two Reagans? Genre imperatives, ghostwriters, and presidential personality profiling. Political Psychology, 23, 839-851.

Sigelman, L. \& Whissell, C. (2002a) "The great communicator" and "the great talker" on the radio: projecting presidential personas. Presidential Studies Quarterly, 32, 137-146.

Sigelman, L. \& Whissell, C. (2002b) Projection presidential personas on the radio: An addendum on the Bushes. Presidential Studies Quarterly, 32,572-576.

Simons, H.W. (2000) A dilemma-centered analysis of Clinton's August $17^{\text {th }}$ apologia: Implications for rhetorical theory and method. Quarterly fournal of Speech, 86, 438-453.

Teten, R.L. (2007) "We the people" The "modern" rhetorical popular address of the presidents during the founding period. Political Research Quarterly, 60, 669-682.

Whissell, C. (1998) A parsimonious technique for the analysis of word-use patterns in English texts and transcripts. Perceptual and Motor Skills, 86, 595-613. 
Whissell, C. (2002) The US Declaration of independence: Emotion, style and authorship. $49^{\text {th }}$ Parallel, 9. (net journal).

Whissell, C. (2009) Using the revised Dictionary of Affect in Language to quantify theemotional undertones of samples of natural language. Psychological Reports, 105, 509-521.

Whissell, C. \& Sigelman, L. (2001) The times and the man as predictors of emotion and style in the inaugural addresses of U.S. presidents. Computers and the Humanities, 35, 255-272.

Whittington, K.E. (1997) The rhetorical presidency, presidential authority, and President Clinton. Perspectives on Political Science, 26, 199-207. 